\title{
Integrated Conservation of the Cantonese Opera Art Museum and Intangible Cultural Heritage
}

\author{
Qian GUO ${ }^{\mathrm{a}}$, Xiaoxue LI ${ }^{\mathrm{b}}$ \\ ${ }^{a}$ School of Architecture, South China of Technology, Guangzhou, China - gqrenders@163.com \\ ${ }^{b}$ School of Architecture, South China of Technology, Guangzhou, China -1455193005@qq.com
}

KEY WORDS: The Cantonese Opera Art Museum, Tangible and Intangible Cultural heritage, Integrated Conservation

\begin{abstract}
:
Cantonese Opera, as the sole cultural heritage of Guangdong Province of China so far, which was included in the World Intangible Cultural Heritage List by the UNESCO, bears the cultural memory of the Lingnan region and as well as the overseas Chinese worldwide. Located in the core historic urban area - Enning Road of Guangzhou, the Cantonese Opera Art Museum is designed in Lingnan traditional garden manner, through going deep into the Cantonese opera culture, Lingnan traditional garden culture and Lingnan cultural spirit. The design highlights the integrated conservation of tangible and intangible cultural heritage, to protect living history and build the historical environment and place spirit for the intangible cultural heritage. The Cantonese Opera Art Museum is not only a tangible space for exhibition, study, education and display of the Cantonese Opera art, but also a cultural space with the Lingnan cultural memory, gathering the Lingnan intangible heritage and closely linked with current life of successors and ordinary people.
\end{abstract}

\section{BACKGROUND}

In October 2002, 7th Regional Assembly of ICOM Asia-Pacific Regional Alliance was held in Shanghai. With the theme of "Museum, Intangible Heritage and Globalization", the Assembly gives importance to the nationality, region and community creativity, adaptability and uniqueness, and make consensus that sound, value, tradition, language, oral history, folk life and so on, should be recognized and promoted in all museums and heritage conservation activities.

On October 17, 2003, the $32^{\text {nd }}$ General Assembly of UNESCO adopted "Convention for the Safeguarding of the Intangible Cultural Heritage". It is the first time that the concept of intangible cultural heritage is explicitly stated. It explains that intangible cultural heritage means the practices, representations, expressions, knowledge, skills - as well as the instruments, objects, artifacts and cultural spaces associated therewith - that communities, groups and, in some cases, individuals recognize as part of their cultural heritage. The intangible cultural heritage, transmitted from generation to generation, is constantly recreated by communities and groups in response to the environment, their interaction with nature and history, and provides them with a sense of identity and continuity. Therefore, it enhances the respect to cultural diversity and human creativity. The Convention clearly points out various measures to protect the vitality of the intangible cultural heritage, including identification, documentation, research, preservation, conservation, promotion, propagation, transmission and revitalization of various aspects of heritage, in particular through formal and informal education. Naturally, museum becomes the most important tangible and cultural space to transmit and protect the intangible cultural heritage. In October, 2004, the General Assembly of ICOM held in South Korea also took the theme of "Museums and Intangible Heritage", which further confirmed the important role of museums in the intangible cultural heritage conservation.

In a series of international charters, museum and intangible cultural heritage conservation are linked together closely. Since the intangible cultural heritage conservation gives more importance to "maximized participation of communities, groups and individuals in creation, continuity 


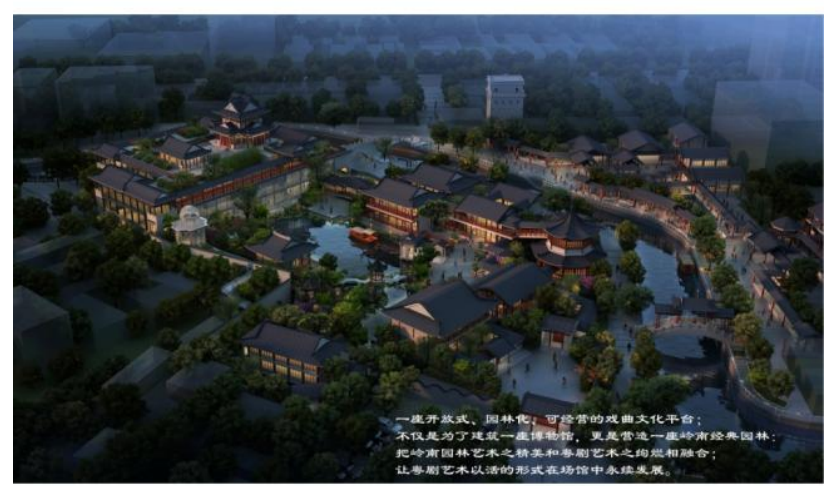

Fig. 1 Design Sketch of the Guangzhou Cantonese Opera

Art Museum

and transmission of the heritage", it has led to function transformation of museums under the influences of new museology. Cultural heritage conservation has changed from mere conservation to tangible objects to integrated conservation of man, object and environment. Now it protects dynamic process of cultural heritage development, rather than the static exhibits for people to pay their respects. Thus, it requires that the museums which bear the function of intangible cultural heritage conservation shall serve as a complex cultural space to inherit intangible cultural heritage and integrate tangible and intangible cultural heritage, rather than just a public building to collect and display cultural relics.

\section{THE CANTONESE OPERA ART MUSEUM AND INTANGIBLE CULTURAL HERITAGE CONSERVATION}

Formed in Guangzhou area, Cantonese Opera is very popular in Guangdong, Guangxi, Hong Kong and Macau. It also spreads to places in Southeast Asia, Americas, Oceania and Europe where overseas Chinese inhabit. It is a Chinese local opera with the most international influence. In 2009, Cantonese Opera, so-called "Red Bean in South China", as a second Chinese opera, was selected in UNESCO Representative List of the Intangible Cultural Heritage of Humanity Comprises Cultural, just following the Kunqu Opera, and is also the sole world intangible cultural heritage of Guangdong Province so far. To safeguard and inherit the endangered Cantonese Opera art, the Guangzhou Municipal Government determines to build the Cantonese Opera Art Museum in Liwan district, the revival area of the Cantonese

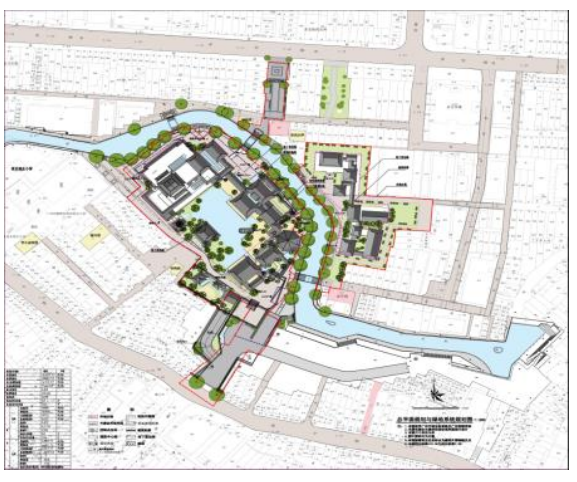

Fig.2 General Plan of the Guangzhou Cantonese Opera Art Museum

Opera, as well as a historical area known as an old name of "Xiguan" in Guangzhou ${ }^{(1)}$.

On the site which was full of Lingnan city characteristics and cultural memory, what kind of architectural form chosen to protect and inherit the world intangible cultural heritage, attracts many Cantonese Opera successors and citizens. After rounds of competitions from 16 design units nationwide, the Lingnan traditional garden, jointly designed by the Architectural Design and Research Institute, South China University of Technology, and Architectural Design and Research Institute of Guangdong Province, is chosen as the final implementation program.

\subsection{Introduction of the Cantonese Opera Art Museum}

As an opera form, the Cantonese Opera is a comprehensive performing art blending singing, reading, performing and stage acrobatic fighting, music, costumes and stages. As the same as the cultural heritage of the traditional garden, Cantonese Opera meets the spiritual needs of the traditional Chinese literati after their substantial requirements were fulfilled. Both the garden and the opera have the same goal to entertain the viewers and satisfy their feelings through artificially created virtual opera/natural space. Virtual story/Landscape cast Chinese literati's recollections and visions on life situation of the viewers and garden owners.

Cantonese Opera and Lingnan garden is geographically active in Liwan river surge-PanTong area, a core historical

(1) The Cantonese Opera Art Museum Design Team: Architectural Design and Research Institute, South China University of Technology; Architectural Design and Research Institute of Guangdong Province 
urban area in Guangzhou. They are part of the historical collective memory in the spirit of Lingnan region.

"Liwan River Surge" is located in the southwest of the old urban area of Guangzhou, and today it specifically refers to "Shangxiguan Rive Surge" to the Pearl River waterway at PanTongkou. In the history of "Liwan River Surge- Pantong area", there were lots of water networks, rivers, lakes, creeks and streams, and Garden was built there in the historical records early in the South Han period. The last Emperor Liu Chang of South Han Dynasty built "Changhua Garden" at Litchi Bay, and whenever litchi became ripe, the Emperor would hold a "Red Cloud Feast" (litchi feast) in the imperial garden, and a part site of his former imperial garden "Liuwang Huawu" was also at Pantong. In the Tang Dynasty, there was a famous garden of "Liyuan". In Jiaqing period of the Qing Dynasty, Qiu Xi built “Qiuzhu Garden” at Litchi Bay, which became the site of the famous Seamount Koon in the later time. In early time of Daoguang period of the Qing Dynasty, since the site of the Tang Dynasty became withered, Ruan Fu, a literate's name, changed the garden's name to "Tangliyuan," and in the later time, a painter named Chen Wuzi drew two paintings "The pictures of Tangliyuan" (Fig.3). As the garden's owner changed, Pan Shicheng owned those two paintings which were stored in The Seamount Koon (Fig. 4). In the Ming Dynasty, "Liwan Fishing song" ( Liwan Yuchang) was one of the eight best sites in Guangzhou, boosting a reputation of "A-thousand-miles of Red Cloud, Eight-bridge Barge". In the Qing Dynasty, "Liwan River Surge" area became an attraction of Guangzhou. During the period of Thirteen-Trades Monopoly, rich families bought gardens along the banks of Litchi Bay and many private gardens appeared represented by The Seamount Koon and the "Little Boats Garden(Xiaohuafangzhai)" (Fig. 5).At the flourishing time, there were various of famous gardens along
"Liwan River Surge", such as "Tangliyuan", "Zhang's garden”, “Song’s Garden”, “Deng’s Garden”, "Lee’s Garden” and "Ye's Garden", etc. Since the Seamount Koon became an official property, it was divided into "Peng's Garden" and "Chen's Garden" The private gardens were not only an important space for meeting friends for merchants but also an important place for recreation of the family members. In his book of "Travel in the Old China", an American named William • Hunter quoted a letter from Guangzhou published in the "French Communique" on April 11, 1860. In the letter, it illustrated the scenes in the Seamount Koon. There was a stage in front of the house where ladies lived. About one hundred actors could perform at the same time on the stage. The stage was so well designed that people could watch shows without any difficulties within the house. There was also a stage built in "Little Boats Garden(Xiaohuafangzhai)". Litchi Bay area is also the location where some of the modern Cantonese Opera performing artists like Hong Xianno, Bai Xuexian, Bai Yurong and Luo Pinchao lived. Within 200 meters from the site, there is the representative of Cantonese opera revival-Bahe Hall (the Chinese actor's association). The site itself has a close connection with Cantonese opera and Lingnan gardens. The Cantonese Opera Art Museum will take advantage of these common and different characters to achieve modern dialogue across time and space between the two arts.

Located in such an important historical urban area, the Cantonese Opera Art Museum appears in the form of the Lingnan traditional garden with the concept of the Chinese traditional art philosophy "rhythmic vitality (Qiyun)”, which pursues the rhythmic combination of the Cantonese Opera

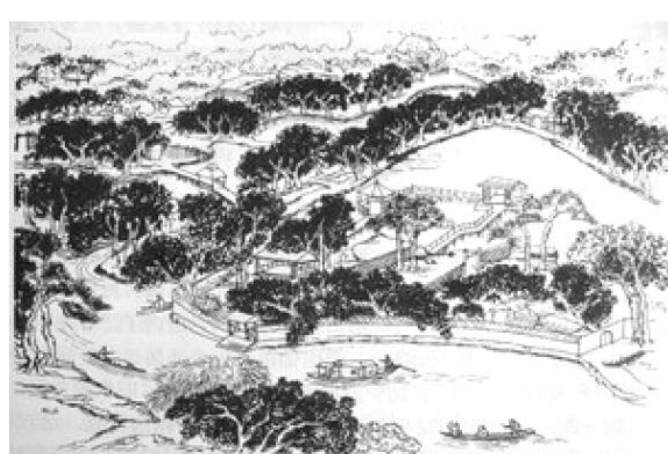

Fig. 3 Tangliyuan Garden

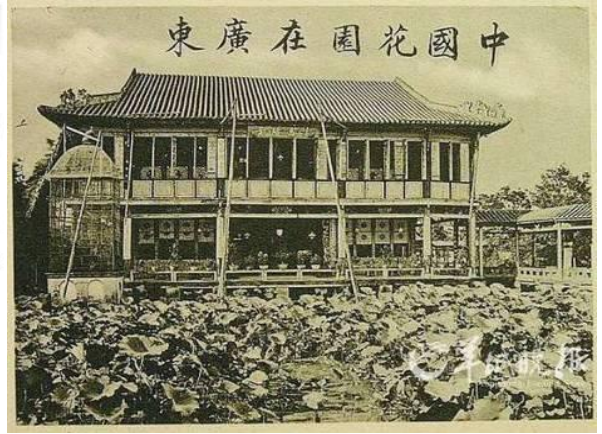

Fig. 4 The Seamount Koon

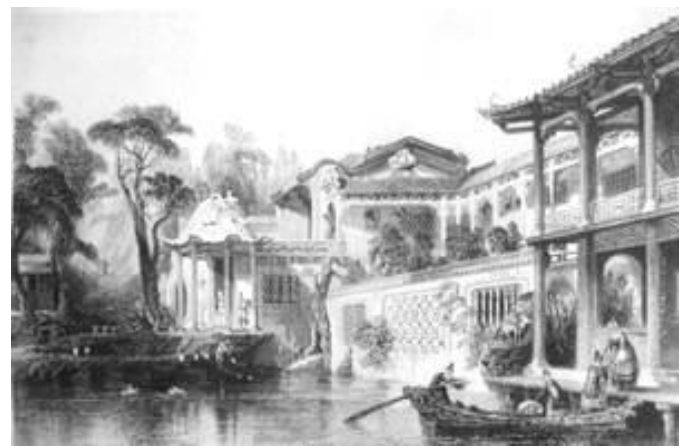

Fig.5 Panchangyao Garden 

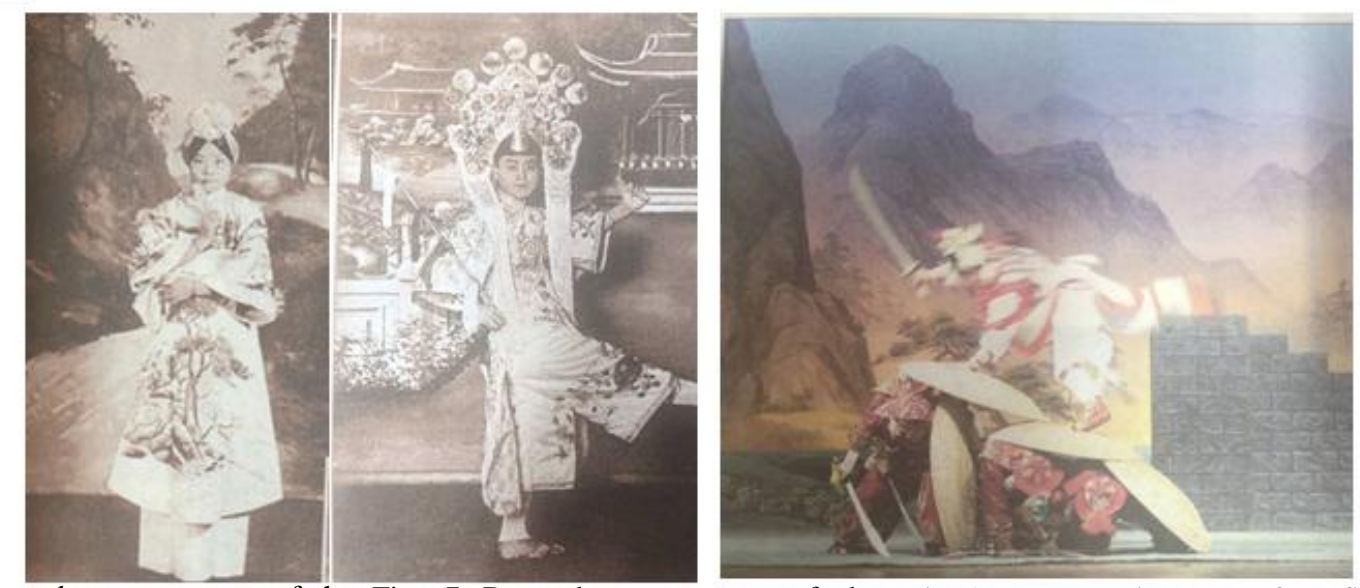

Fig. 6 Dressed young actress of the Fig. 7 Dressed young actor of the Fig. 8 Da-teng-pai (a way of act fighting

Cantonese Opera in late $19^{\text {th }}$ century Cantonese Opera in late $19^{\text {th }}$ century in Cantonese Opera)

and Lingnan garden art in the spirit and architectural performance. The building includes the main building and six groups of gardens. The overall layout of the building group is located along the skeleton of the cross axis: the longitudinal axis is determined based on the hall and the pavilions. The west of the axis is designed for exhibition and large-scale performances, while the east of the axis for recreation, temporary exhibition and small-scale performances. Six groups of courtyards are designed a spatial layout to closely surround the central pond like a myriad of stars around the moon. The central pond form an water area up to $1478 \mathrm{~m}^{2}$, with the diversion from "Liwan River surge", accounting for $12.8 \%$ of the site. The water flowing through each courtyard will connect to the central water area, so the entire space will joint up. Gardens, buildings hills and water arrangement are all based on the "rhythmic vitality (Qiyun)" as the concepts, thus make the whole garden lively.

\subsection{Integrated Preservation of the Cantonese Opera Art Museum and the Intangible Cultural Heritage}

With the reference to the five major contents of the intangible cultural heritage in the "Convention for the Safeguarding of the Intangible Cultural Heritage", the Cantonese Opera mainly covers the oral traditions and expressions, performing arts, ritual festival activities, and traditional handcrafts and so on. When we take the Cantonese Opera Art Museum as an objective to inherit and develop the cultural space of the Cantonese opera, we found Lingnan traditional garden become the best choice for the transmission and development of the intangible cultural heritage.

The crucial point of sustainable development of the intangible cultural heritage is in living development process, which need to correlate with the current common life. In addition to focusing on the tangible culture conservation, it is more important to protect the historical environment and place spirit where the cultural heritage locates, which is required to emphasize in domestic cultural heritage conservation fields in recent years. Only when it is always associated with common life of the successors and ordinary people, can the intangible cultural heritage be inherited and carried on along with times. What we shall safegard is just those living development processes, rather than the rigid conservation of one piece of exhibition, a costume or only making some virtual settings for the generations.

As an opera museum, the Cantonese Opera Art Museum give priority to the opera place spirit. In addition to the exhibition space underground, small theater attached to the main hall for exhibitions, performances, education and research, six groups of courtyards build an overall opera atmosphere. There is not only a waterside stage - GuangFu stage to reproduce opera performance space in the garden, but also all the courtyards, waterside, hills, corridors and winding paths to serve as folk-performances sites. The entire Cantonese Opera Art Museum will build the most possible opera space for transmission of the intangible cultural heritage. It will become a place for artists, professional performers and masses for gathering and singing the opera. The opera's connotation "life is like a drama, and vice versa" can be found throughout the scene design of the garden. The theme-scene design of the garden is inspired by famous sections of some Cantonese Opera, together with the 
Lingnan's traditional crafts, Hills, pools and plants create a virtual sense like a real theater stage settings and the opera atmosphere of permeates in details.

The exhibition for tangible cultural heritage is a challenge to the museum. Since the retained high-class exhibits of Cantonese Opera are limited, most of them are reproductions of performing props, documents and pictures, which fail to represent the real historical scenes of Cantonese Opera. Therefore, the museum should reflect the spirit of Lingnan culture through spread on the whole Lingnan region, since Cantonese opera art is on behalf of the intangible cultural heritage in Lingnan region. It shall not only protect and inherit Cantonese Opera art, but also include the important intangible cultural heritage and related historic environment in the Lingnan region.

In addition to traditional exhibition ways of relics, multimedia presentations and indoor settings, on the experience design, the Cantonese Opera Art Museum will bring the whole garden atmosphere into all the exhibition hall, to make inside and outside merge together, just like travelling in the garden. An open Lingnan traditional garden becomes a multivariate space to experience all kinds of the intangible cultural heritage in Lingnan region. In architectural decoration, some of the intangible cultural heritage successors in Lingnan traditional architecture Sculpture (woodcarving, brick carving and stone carving) and Clay Sculpture, are engaged to make thematic works for the museum. The traditional crafts and their production processes in Lingnan region, such as Chaozhou woodcarving, Cantonese woodcarving, brick carving, stone carving, clay sculpture, and Shiwan pottery sculpture also become the contemporary collections of the museum. At the same time, the natural, cultural and community environment, such as tangible spaces and ritual festival activities, which is related with Cantonese Opera, are the important objects to be protected by the museum. In particular, the traditional Opera God space for "the God Huaguang" is settled at Guangfu stage as the Cantonese Opera's tradition and the folk intangible cultural heritage successors are invited to engage in the process, in order to continue the performance of god-thanksgiving ceremony after the museum operation. During the period of main building construction, a traditional roof-beam-setting (Shangliang) ceremony is held in accordance with the folk tradition of the Lingnan region. There is no doubt that the Cantonese Opera Art Museum would become an important integrated place of the tangible and intangible cultural heritage in the Lingnan region.

Cantonese Opera is a representative of the spirit of Lingnan culture, which means secularity, openness and innovation, mirroring the economical and pragmatic spirit of the Lingnan region. The singing, stage performing form and costumes of Cantonese Opera are close to the folk life style, and as compared with Jiangnan Gardens, Lingnan gardens are more close to the ordinary people, more relaxing and open. Therefore, "closely related with ordinary people's lives" becomes a fundamental principle for cultural space design of the Cantonese Opera Art Museum. So in addition to the functions of "exhibitions, performances, education and research", based on the new concept of the museology ,the museum takes the "public participation and secular Life" as the most important rule, the cultural space design of the museum must serve to the opera transmission activities and
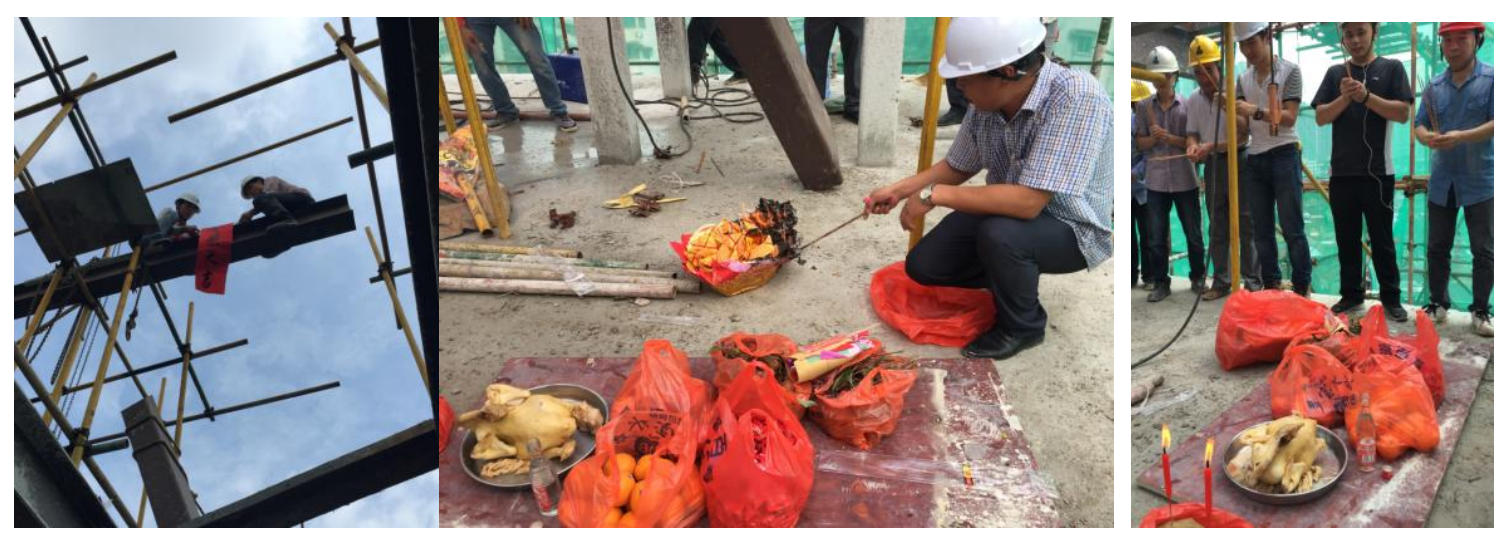

Fig. 9 Traditional roof-beam（ShangLiang） ceremony held at the Cantonese Opera Art Museum 
the daily life of the successors and ordinary people.

In addition to physical research space and academic communication space, the Cantonese Opera Art Museum shall provide an open network database and files archives. Thanks to the independent space of the six groups of courtyards, it can provides independent spaces for professionals and folk performers for art exchange and education. Meanwhile, also for small theater, digital multimedia and public service activities in community, thus making the museum become a "Social Classroom" for citizens and communities to carry out popularization, education and conservation of the traditional culture. Moreover, since the six groups of courtyards can be operated independently, a private party of folk show("Sihuoju") can be held after the museum closed. To express Guangzhou food culture into the museum, the courtyard near the south entrance for teahouse can be open all year round,. which can provide public services, and also restore the traditional memories of old Guangzhou featured by watching the opera while drinking tea in the Lingnan teahouse, embodying the close relation between the opera and the daily life of Lingnan people. The opera can be inherited and sustainable developed with the living life. Although in the Lingnan traditional garden form, the museum attaches importance to the continuation and public nature of contemporary life. The main hall is designed with a public corridor where former citizen market pathway is maintained on the site, thereby making a open walkways which have a close connection with the urban roads. In this way, the local residents can enjoy the traditional garden in daily life as well as the urban public space. More importantly, it can carry on a traditional life memory of living in an old street in the past. As a result, the Cantonese Opera Art Museum will become an integral place that full of historical memory and contemporary life.

In the transformation design for its surrounding environment, the museum is planned to expand the garden atmosphere in the museum to the surroundings, so as to create an "urban landscape" concept. Which it is consistent with the history and the present situation. Meanwhile, in the surrounding business planning, the Cantonese Opera cultural transmission institutions, the Cantonese Opera cultural and educational space, cultural and creative industries and services are settled. As a result, cultural influence of the museum will penetrate into the entire community .A community museum without walls will be established.

\section{CONCLUSION}

To build an inheritance atmosphere for Cantonese Opera and the Lingnan intangible cultural heritage in the future, he Cantonese Opera Art Museum is not only in accordance with the cultural spirit of the Lingnan region, but also complies with an open, inclusive and pluralistic spirit of the times. It is not only a center for exhibition, study, education and performance for the Cantonese Opera, but also a cultural space closely related with the life of successors and citizens. Only rooted in the soil of people's daily life ,integrated tangible and the intangible cultural heritage, Cantonese Opera will can be safeguarded and inherited developed along with the time.

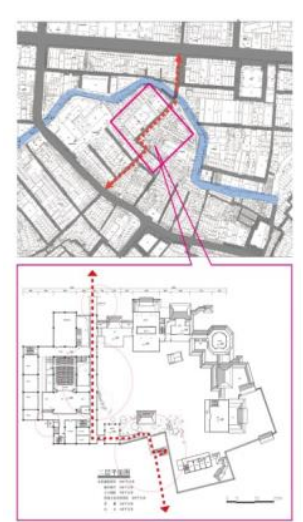

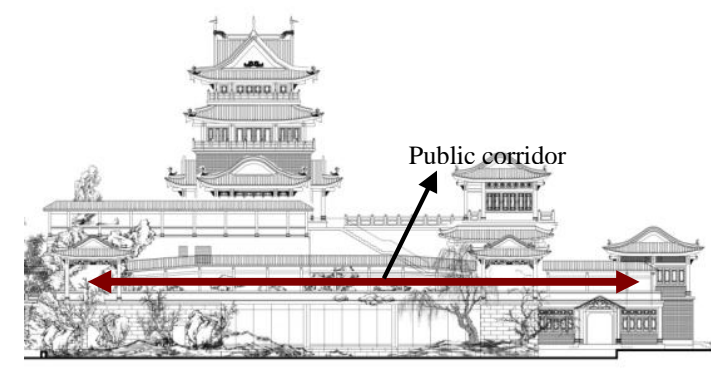

Fig. 10 A public corridor is provided in the main hall design according to field study

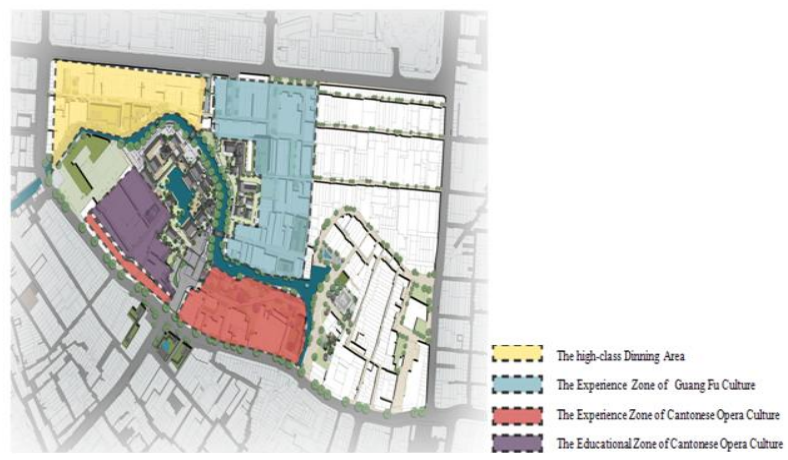

Fig. 11: The Surrounding business planning of the Cantonese Opera Art Museum 
The International Archives of the Photogrammetry, Remote Sensing and Spatial Information Sciences, Volume XL-5/W7, 2015 25th International CIPA Symposium 2015, 31 August - 04 September 2015, Taipei, Taiwan

\section{REFERENCES}

Guo Qian, Wan Fengdeng, Xu Xiaojing, 2013. A Poetic Artistic Conception on the Extension and Regeneration of History: The Design Process Record of Cantonese Opera Art Museum . South Architecture, 2013 (3): 60-63.

Hu Dongxiang, 2007. Guangzhou Modern Landscape of Guangzhou: PHD Thesis of South China University of Technology. 